\title{
Antimicrobial Activity of Rumex Nepalensis and Urtica Diocia
}

\author{
Muhammad Waqas ${ }^{1}$, Madia ayaz ${ }^{2}$, Salma Afridi ${ }^{3}$, Nisar Ahmad $^{4}$, Mian Amir Sohail ${ }^{5}$, Azam Hayat ${ }^{6}$, \\ Rahdia Ramzan , and Muhammad Ayub Jadoon ${ }^{8}$ Mujaddad-ur-Rehman ${ }^{9}$, Muhammad Niaz ${ }^{10}$ \\ 1, 3, 4, 5, 6, 7, 8, 9, 10 Department of Microbiology, Abbottabad University of Science and Technology, Havelian, Abbottabad, KPK, Pakistan
}

${ }^{2}$ Ayub Medical Complex, Abbottabad, KPK, Pakistan

\begin{abstract}
Two herbaceous plants named Urtica diocia and Rumex nepalensis were selected for checking their antimicrobial activity. Also observing their opposite action on humans when extracts were applied on skin. The extracts were prepared in 95 percent ethyl acetate, 70 percent methanol and boiled water. After drying the leaves and roots of selected plants, the $U$. diocia extracts were prepared by using 95 percent ethyl acetate and boiled water while the $R$. nepalensis extracts were prepared in 70 percent methanol. U. diocia have the inflammatory response when applied on skin while the Rumex have opposite action by removing the symptoms of Urtica extracts when applied on skin. The anti microbial activity was also tested for both plants extracts against selected strains of organisms which were Escherichia coli, Pseudomonas aeruginosa, Candida albicans, Klebsiella pneumoniae and MRSA (Methicillin-resistant Staphylococcus aureus) for extracts of Rumex nepalensis. The clear zone on nutrient agar when leaves extract of R. nepalensis were applied against these organisms which were E.coli 15mm, Pseudomonas aeruginosa 15mm, Candida albicans 13mm, MRSA 9mm and Klebsiella pneumoniae $7 \mathrm{~mm}$. Roots extracts of R. nepalensis shows $19 \mathrm{~mm}$ E.coli, $9 \mathrm{~mm}$ Pseudomonas aeruginosa, 16mm Candida albicans, $12 \mathrm{~mm}$ MRSA and $12 \mathrm{~mm}$ for Klebsiella pneumoniae clear zones were appeared on nutrient agar. E.coli, Pseudomonas aeruginosa, Bacillus cereus, MRSA and Enterococcus faecalis were tested for the extracts of U. diocia. The U. diocia extracts in boiled water were sensitive against these selected organisms but the ethyl acetate extracts shows the clear zone which were $9 \mathrm{~mm}$ E.coli, 10mm Pseudomonas aeruginosa, $19 \mathrm{~mm}$ B.cereus, $17 \mathrm{~mm}$ MRSA and $13 \mathrm{~mm}$ E.faecalis due to leaves extract of $U$. diocia while roots extracts of U. diocia shows $10 \mathrm{~mm}$ E.coli, $12 \mathrm{~mm}$ Pseudomonas aeruginosa, 13mm B.cereus, $7 \mathrm{~mm}$ E.faecalis zones appeared against these organisms. Only MRSA are resistive to roots extracts of $U$. diocia.
\end{abstract}

\section{Introduction}

Urtica diocia also known as stinging nettle belongs to family Urticaceae and its genera is Urtica which is an herbaceous flowering plant, with height of $30-100 \mathrm{~cm}$. It is mostly found in Europe, Asia, North Africa, and Northern America. The green and erect stem of $U$. diocia which have opposite leaves which are dark green above and pale beneath (Brill and Dean, 1994). Traditional uses of $U$. diocia is against diabetes while also used against some other diseases like prostatic hyperplasia, inflammatory responses (Krzeski et al., 1993), rheumatoid arthritis and allergic rhinitis (Miltman, 1990), while also used as a pivotal treatment in those patients having sinusitis (Helms and Miller, 2006). $U$. diocia contains many compounds such as vitamin C, polysaccharids, carotene, betasitosterol, rutin, kaempferol, flavonoids quercetin, trans-ferulic acid, dotriacotane, ursolic acid, scopoletin, rutin, and p-hydroxylbenzalcohol (Ji et al., 2007). It is believed about the Nettle is that it is galactagogue (Westfall, 2003) which can minimize TNF-Y and also inflammatory cytokines (Obertreis et al., 1996).

$U$. diocia plant is beneficial as well as having some side effects that is also having inflammatory response when touch to skin. But there is no research on such aspects of this plant. We planned this research to evaluate such aspect of this plant.

The Rumex is genus which contains about 200 species of herbs. One of specie is Rumex nepalensis Spreng from Polygonaceae family commonly known as "jungle palak". It occurs at altitudes between $1200-4300 \mathrm{~m}$. $R$. nepalensis Spreng is perennial herbs having large roots and erect stems which is $50-100 \mathrm{~cm}$ tall. Its leaves structure is basal and petiole is 4-10 cm (AnjenLi et al., 2003). R. nepalensis is medicinal plant mostly its leaf extract is applied to cure skin sores and also leaf infusion is given in colic and applied to syphilitic ulcers. The root is given to animals for treatment of diarrhoea and dysentery. Leaf powder is also used to treat scabies when mixed with butter (Manandhar, 1995). Its aqueous extract may also used as wash for reducing body pain (Shrestha, 1993). R. nepalensis roots shows purgative (Ghosh et al., 2003], analgesic, antipyretic (Datta et al., 2003), anti-inflammatory (Gautam et al., 2010) and psychopharmacological activities (Ghosh et al., 2002).

$R$. nepalensis have anti inflammatory response so this study is about evaluating the anti inflammatory response of this plant. Also in this study we observed the anti sense activity of both plant $U$. diocia and $R$. nepalensis. As we mentioned $U$. diocia has inflammatory response and Rumex has anti inflammatory response so we designed this study to see the action of both plants.

\section{Objectives}

- Plant collection.

- Plants extraction (Roots and Leaves).

- Antibacterial activity.

\section{Sampling and Extraction of Different Parts of Plants}

Mature plant of Urtica diocia was collected from Nathiagali in the month of November 2015 and identified in Department of Microbiology, Abbottabad University of science and technology by Doctor Mujaddad. The extraction 


\section{International Journal of Science and Research (IJSR) \\ ISSN (Online): 2319-7064 \\ Index Copernicus Value (2013): 6.14 | Impact Factor (2014): 5.611}

process of roots and leaves of Urtica diocia includes first to dry the fresh plant by leaving it at room temperature for at least 7 days. After drying the leaves and root, they were then crushed into powder. $2 \mathrm{gm}$ of the roots and leaves powder was placed in $100 \mathrm{ml}$ water which were boiled and then leave it for 1 hour and filter them into a flask by passing through Whatman No.1 filter paper (Barnes et al., 2007).

Dried leaves of Urtica diocia (1 gm) and dried roots powder (2gm) were taken and soaked in $20 \mathrm{ml}$ of $95 \%$ ethyl acetate, and then place on shaker for $24 \mathrm{hrs}$ at $150 \mathrm{rpm}$. at ambient temperature. The extract was then filtered by using Whatman No.1 filter paper. The extract was then concentrated for storage to near dryness in low pressure at below $40 \mathrm{oC}$ through use of rotary evaporator. For storage of these extracts they were diluted in about $20 \mathrm{mg} / \mathrm{ml}$ of 10 percent dimethyl sulfoxide solution and store in glass bottles which was air tight in a refrigerator for further studies (Mingarro et al., 2003).
The mature green plants of Rumex nepalensis were collected from Abbottabad region, Pakistan in the month of November 2015. The plant was identified in Department of Microbiology, Abbottabad University of science and technology by Doctor Mujaddad. After authentification, the fresh leaves and roots were dried under shade at room temperature for 20 days and pulverized in a grinder. The coarse powder was used for further research studies as in figure 1 and 2. Methanolic extract was prepared from coarse powder of leaves and roots of Rumex nepalensis (MERN), by soaking the dried coarse powdered with $20 \mathrm{gm}$ of each plant in $100 \mathrm{ml} 70 \%$ methanol and were filtered through whatmann filter paper after macerating for three days. The extract was first concentrated and then stored in a refrigerator at $5^{\circ} \mathrm{C}$ for experimentation. The methanolic extracts of the plants were dissolved in dimethyl sulphoxide (DMSO) at the concentration of $10 \mathrm{mg} / \mathrm{ml}$ (Hussain et al., 2010).

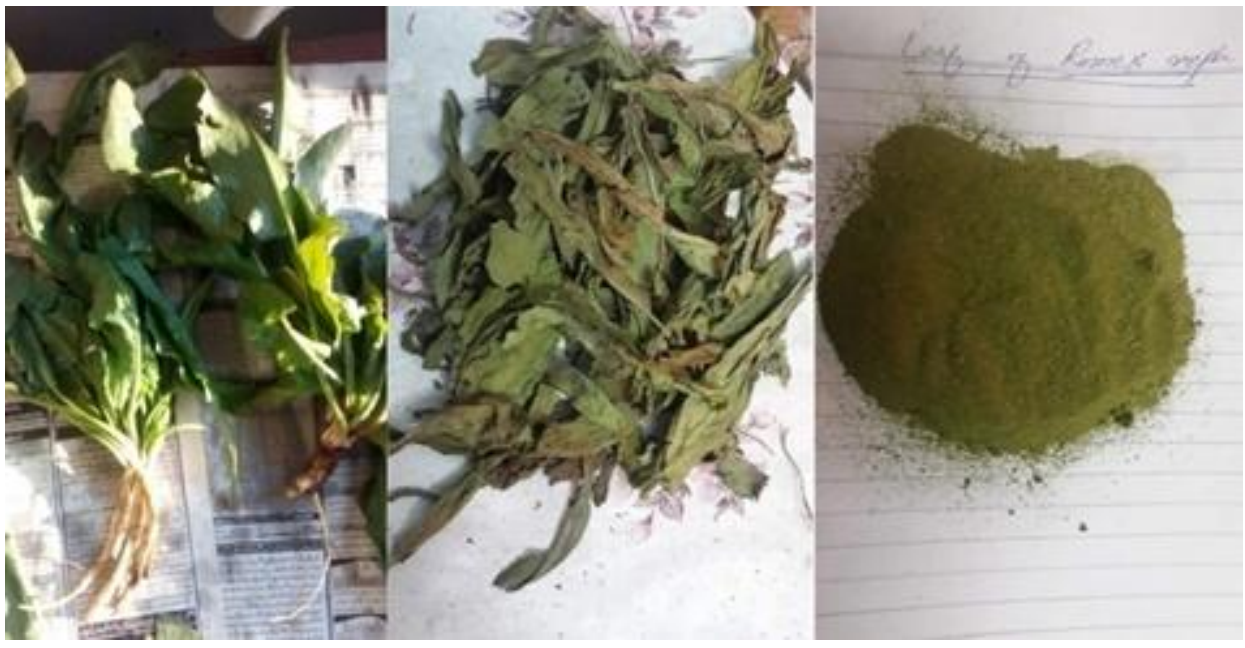

Figure 1: Fresh, Dry and Powder of leaves of Rumex Nepalensis Plant

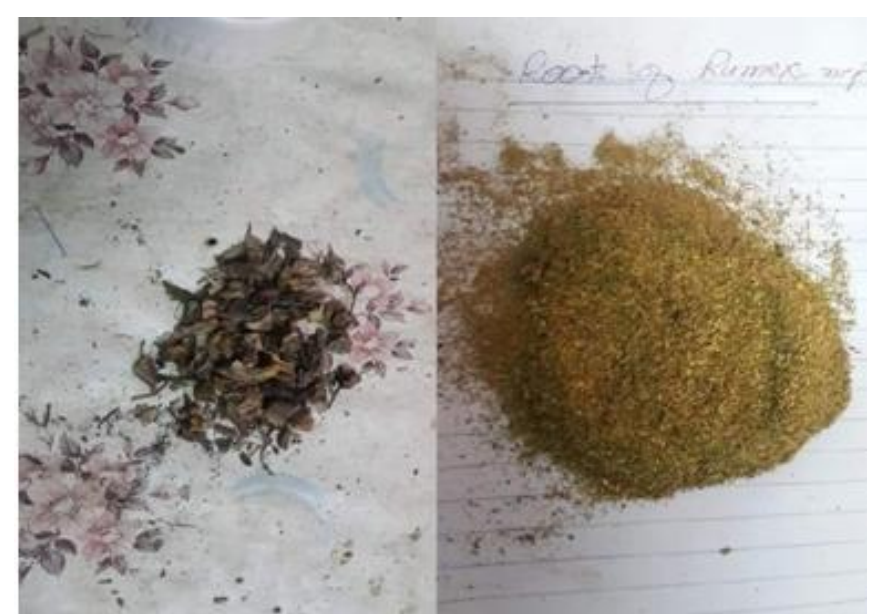

Figure 2: Dry and Powder of Roots of Rumex nepalensis

\section{Symptoms}

The extract of Urtica diocia (figure 3) was first applied on skin which brings inflammatory response on skin within 2 to 3 minutes. After appearing its symptoms we then apply the extract of Rumex nepalensis (figure 3) on that portion of skin which removes the response of Urtica extract within 10 to 15 minutes.

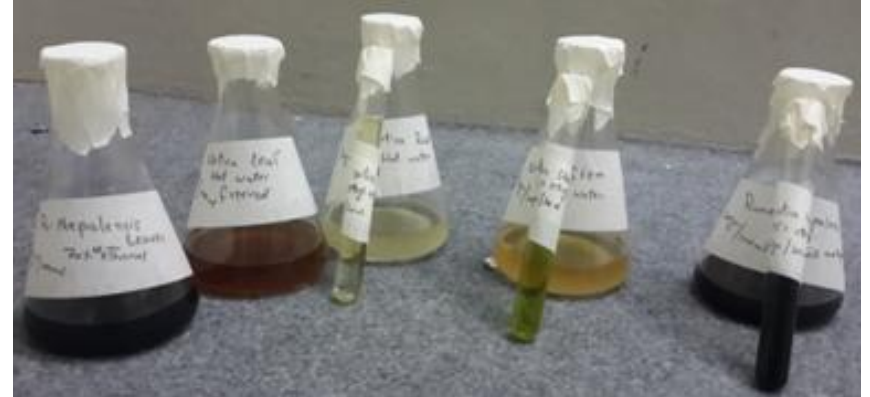

Figure 3: Extracts of Rumex nepalensis and Urtica diocoa

\section{Well Diffusion Method}

Well diffusion method as used for analysis of sensitivity test of these extracts against selected microorganisms i.e. checking its Antibacterial and antifungal activities. First selected strains of microorganisms (bacteria and fungi) were cultured on nutrient agar plates by using streak plate method and then wells of about $6 \mathrm{~mm}$ were made on nutrient plates inoculated with selected microorganisms. The wells were then filled b extracts prepared from roots and leaves of Rumex nepalensis and U. diocia and incubate for overnight. Selected bacteria are Echerichia coli, MRSA, Enterococcus faecalis, Pseudomonas aeruginosa, Klebsiella pneumoniae, 


\section{International Journal of Science and Research (IJSR) \\ ISSN (Online): 2319-7064 \\ Index Copernicus Value (2013): 6.14 | Impact Factor (2014): 5.611}

Bacillus cereus and fungus is Candida albicans. The plates having bacterial culture were placed in incubator at $37^{\circ} \mathrm{C}$ for 24 hours while for fungal cultured plates incubated at $25^{\circ} \mathrm{C}$ for 48 hours. The next day plates were taken out from incubator and the clear zones around wells were measured in mm by using scale.

The methanolic extract of $R$. nepalensi, while hot water and ethyl acetate extract of $U$. diocia was used for the study. The methanolic extract was applied to sterile wells at a concentration of $300 \mu \mathrm{g} /$ well while ethyl acetate and hot water extract of $\mathrm{U}$. diocia were used in concentration of $200 \mu \mathrm{g} /$ well and its antibacterial and antifungal activity were tested by using well diffusion assay. The clear zone which appeared around the wells are called zone of inhibition which were measured in mm by using scale. (Zaheer et al., 2010).

\section{Results}

Both plants extracts were applied on different bacteria and observe their anti microbial activity and the clear zone appeared on plates were measured in $\mathrm{mm}$ and noted as shows in table 1 and 2 and also in figure4.

The R. nepalensis leaves and roots extracts were applied on E.coli, Pseudomonas aeruginosa, Candida albicans, Klebsiella pneumoniae and MRSA. These organisms were cultured on nutrient agar and about $6 \mathrm{~mm}$ wells were made on cork borer on media plates and then after making the wells in media plates the prepared extracts were poured in each wells made on plates against each bacteria. About $300 \mu \mathrm{g} /$ well of each extracts of R. nepalensis and $200 \mu \mathrm{g} /$ well of $\mathrm{U}$. diocia extracts were poured in wells.

The leaves extract of nepalensis shows $15 \mathrm{~mm}$ of clear zone against E.coli on nutrient agar, against P.aeruginosa $15 \mathrm{~mm}$ of clear zone appeared, 13mm zone appeared against Candida, $7 \mathrm{~mm}$ against Klebsiella pneumoniae and $9 \mathrm{~mm}$ zone appeared against MRSA. Thus showing the anti microbial activity. As compared to leaves of nepalensis the roots shows more anti microbial activity against same microbes used for leaves extract. The root extract shows the clear zones against these bacteria are E.coli $19 \mathrm{~mm}$, P.aeruginosa $9 \mathrm{~mm}$, Candida $16 \mathrm{~mm}$, K. pneumoniae $12 \mathrm{~mm}$ and MRSA $12 \mathrm{~mm}$.

Table 1: Antibacterial Activity of Rumex Nepalensis

\begin{tabular}{|c|c|c|c|}
\hline S. No & Microorganisms & Leaves & Roots \\
\hline 1 & Echerichia coli & $15 \mathrm{~mm}$ & $19 \mathrm{~mm}$ \\
\hline 2 & Pseudomonas aeruginosa & $15 \mathrm{~mm}$ & $9 \mathrm{~mm}$ \\
\hline 3 & Candida albicans & $13 \mathrm{~mm}$ & $16 \mathrm{~mm}$ \\
\hline 4 & MRSA & $9 \mathrm{~mm}$ & $12 \mathrm{~mm}$ \\
\hline 5 & Klebsiella pneumoniae & $7 \mathrm{~mm}$ & $12 \mathrm{~mm}$ \\
\hline
\end{tabular}

The extracts of U. diocia in hot water shows no sensitivity to an selected organisms while the extracts in 95 percent ethyl acetate shows the activity against the selected organism which were E.coli, P. aeruginosa, B.cereus, E. faecalis and MRSA. The leaves extracts of U. diocia in ethyl acetate after applying on nutrient agar of about $200 \mu \mathrm{g} /$ well against selected microbes shows the clear zone which shows its anti microbial activity. The zones were measured in mm which are $9 \mathrm{~mm}$ against E.coli, $10 \mathrm{~mm}$ against $\mathrm{P}$. aeruginosa, $19 \mathrm{~mm}$ for B.cerues, and $13 \mathrm{~mm}$ against E.faecalis and $17 \mathrm{~mm}$ against MRSA. The roots extract of $U$. diocia in ethyl acetate were resistive against MRSA in $200 \mu \mathrm{g} /$ well quantity which shows no clear zone on nutrient agar while sensitive against other microorganisms and shows the zones which were $10 \mathrm{~mm}$ against E.coli, $13 \mathrm{~mm}$ for B.cereus, $7 \mathrm{~mm}$ for E.faecalis and $12 \mathrm{~mm}$ against $\mathrm{P}$. aeruginosa shown in table2.

Table 2: Antibacterial Activity Of Urtica Diocia

\begin{tabular}{|c|c|c|c|}
\hline S. No & Microorganisms & Leaves & Roots \\
\hline 1 & E.Coli & $9 \mathrm{~mm}$ & $10 \mathrm{~mm}$ \\
\hline 2 & Pseudomonas aeruginosa & $10 \mathrm{~mm}$ & $12 \mathrm{~mm}$ \\
\hline 3 & Bacillus cereus & $19 \mathrm{~mm}$ & $13 \mathrm{~mm}$ \\
\hline 4 & MRSA & $17 \mathrm{~mm}$ & $0 \mathrm{~mm}$ \\
\hline 5 & Enterococcus faecalis & $13 \mathrm{~mm}$ & $7 \mathrm{~mm}$ \\
\hline
\end{tabular}

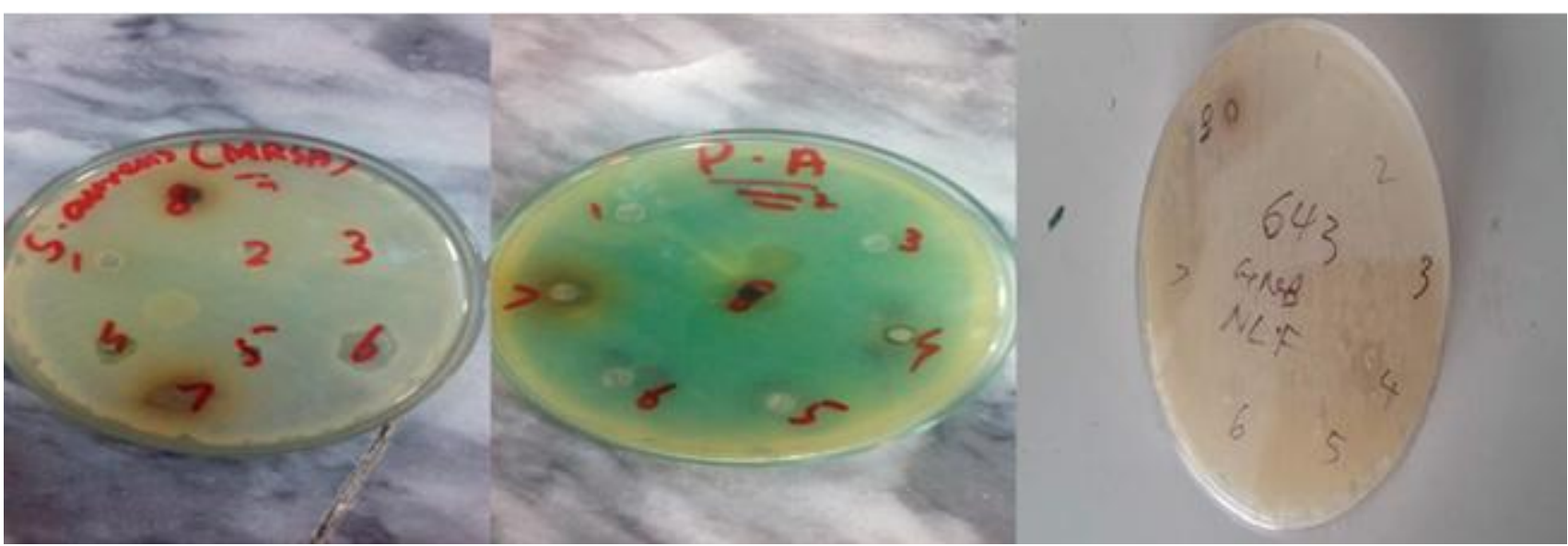

Figure 4: Sensitivity Test of all Extracts of Rumex Nepalensis and Urtica diocia against selected organisms

\section{Discussion}

The extracts of $\mathrm{R}$. nepalensis in $70 \%$ methanol while $\mathrm{U}$. diocia in hot water and 95\% ethyl acetate were prepared and filtered and stored. After preparing the extracts the nutrient plates were taken and cultured by spreading technique using sterile swab. For R. nepalensis the organisms which were cultured on nutrient plates were E.coli, P. aeruginosa, MRSA, K. pneumoniae and Candida albicans. First of all each of these microbes were cultured on nutrient agar plates. 


\section{International Journal of Science and Research (IJSR) \\ ISSN (Online): 2319-7064 \\ Index Copernicus Value (2013): 6.14 | Impact Factor (2014): 5.611}

Then in each plate wells of about $6 \mathrm{~mm}$ were made by cork borer. The negative and positive control was also applied on nutrient agar for checking the control of our extracts and its results.

After making the wells, the extracts of roots and leaves of $\mathrm{R}$. nepalensis were poured in each well of about $300 \mu \mathrm{g} /$ well of each extracts were poured in wells and then the plates were placed in incubator for overnight. The next day the plates were taken from incubator and note the clear zones appeared against these bacteria due to these extracts. They were measured in mm by using scale which was shown in tables above.

The leaves of R. nepalensis show the highest zones against E.coli while the roots show against MRSA the highest zone which shows that leaves have antibacterial activity against gram negative bacteria while roots have such chemicals which mostly shows the activity against the gram positive bacteria.

The extracts of U. diocia leaves and roots were prepared in hot water and 95 percent ethyl acetate. Wells were made b a cork borer of about $6 \mathrm{~mm}$ in which about $200 \mu \mathrm{g} /$ well of extracts of roots and leaves were poured in both hot water and ethyl acetate on separate plates having nutrient agar first inoculated with our selected organisms which were E.coli, B. cereus, E. faecalis, P. aeruginosa and MRSA. The extracts of leaves and roots of U. diocia prepared in hot water were poured in wells while also on other plates separately the other extracts prepared in ethyl acetate were poured in wells. About $200 \mu \mathrm{g} /$ well of each of extracts of leaves and roots were poured in wells made in nutrient agar. the wells contain the hot water extract of U. diocia shows no clear zone after incubation of plates which shows that extracts in hot water have no antimicrobial activity against selected microorganisms.

The extracts which were prepared in 95 percent ethyl acetate shows the clear zone when observed after incubation of plates. The clear zones which were appeared due to leaf extract of U. diocia were measured in $\mathrm{mm}$ by using scale which was about $9 \mathrm{~mm}$ for E.coli, 10 for Pseudomonas, $19 \mathrm{~mm}$ for B.cerues, 13mm against E.faecalis and 7 for MRSA. The root extract of Urtica in ethyl acetate also shows no clear zone against the MRSA which means MRSA are resistive to root extract of Urtica. Against other microorganisms the root shows the clear zone which was $10 \mathrm{~mm}$ for E.coli, $13 \mathrm{~mm}$ for B.cereus, and $7 \mathrm{~mm}$ for E.faecalis and $12 \mathrm{~mm}$ for P. aeruginosa. This study shows that U. diocia extracts are mostly sensitive against Pseudomonas species.

\section{References}

[1] Anjen, L., Alisa, E., Grabovskaya, B., Sergei, L. and Mosyakin. (2003). Rumex Linnaeus,,Flora of china ${ }^{e e}$. Science Press: Beijing, China; Missouri Botanical Garden Press: St. Louis, Missouri, USA, 5; 333-341.

[2] Datta, L., Chttopadhyay, S., Das, J., Saha, B. P. and Pal, M. (2003). Evaluation Of Analgesic And Antipyretic Potential Of The Roots Of Rumex Nepalensis Spreng. Indian Journal of Pharmacology, 35; 194-201.
[3] Farrukh, H., Bashir, A., Ishfaq, H., Ghulam, D., Parveen, S. and Sadiq, A. (2010). Antibacterial, antifungal and insecticidal activities of some selected medicinal plants of polygonaceae. African Journal of Biotechnology, 9(31); 5032-5036.

[4] Gautam, R., Karkhile, K. V., Bhutani, K. K. and Jachak, S. M. (2010). Anti-inflammatory, cyclooxygenase (COX)-2, COX-1 inhibitory, and free radical scavenging effects of Rumex nepalensis. Planta Med, 76(14); 1564-1569.

[5] Ghosh, L., Arunachalam, G., Murugesan, T. and Saha, B. P. (2002). Studies on the psychopharmacological activities of Rumex nepalensis Spreng. root extract in rats and mice. Phytomedicine, 9(3); 202-206.

[6] Ghosh, L., Gayen, J. R., Murugesan, T., Sinha, S. and Saha, B. P. (2003). Evaluation of purgative activity of roots of Rumex nepalensis. Fitoterapia, 74; 372-374.

[7] Helms, S. and Miller, A. (2006). Natural treatment of chronic rhinosinusitis. Altern Med Rev, 11(3); 196-207.

[8] Ji, T., Liu, C., Wang, A., Yang, J., Su, Y., Yuan, L. and Feng, X. (2007). Studies on the chemical constituents of Urtica dioica L. grown in Tibet Autonomous Region. Zhong Yao Cai Jur, 30; 662-664.

[9] Krzeski, T., Kazon, M., Bordowski, A., witeska, A. and Kuczera, J. (1993). Combined extracts of Urtica dioica and pygeum africanum in treatment of bening prostatic hyperplasia: double-blind comparison of two doses. Clin Therapeut, 15; 1011-1020.

[10] Manandhar, N. P. (1995). A survey of medicinal plants of jajarkot district, Nepal. Journal of Ethnopharmacology, 48(1); 1-6.

[11] Miltman, P. (1990). Randomized double blind study of freeze dried Urtica dioica in the treatment of allergic rhinitis. Planta Medica, 56; 44-47.

[12] Mingarro, D. M., Acero, N., Linares, F., Pozuelo, J. M., Mera, A. C. and Peres, C. (2003). Biological activities from Catalen bignonoides walt. (Bignonieceae). J Ethnopharmacol, 87; 163-167.

[13] Obertreis, B., Giller, K., Teucher, T., Behnke, B. and Schmits, H. (1996). Antiinflammtory effect of Urtica dioica folia extract in comparison to caffeic malic acid. Arzneimittelforschung, 46; 52-56.

[14] Shrestha, I. and Joshi, N. (1993). medicinal plants of the lele village of lalitpur district, Nepal. Int. J. Pharmacogn, 3(1); 130-134.

[15] Westfall, E. (2003). Galactagogue herbs: a qualitative study and review. Canadian Journal of Midwifery Res Pract, 22; 22-27.

[16]Zaheer, Z., Khan, S. W., Patel, K. A., Konale, A. G. and Lokre, S. S. (2010). Antimicrobial activity of essential oil of flowers of Plumeria alba Linn (Apocynaceae). Int J Pharm Pharm Sci, 2(4); 155-157. 